\author{
P. T. Beyli ${ }^{1}$, M. Doğan ${ }^{1 *}$, Z. Gündüz ${ }^{2}$, M. Alkan ${ }^{3}$ Y. Turhan ${ }^{1}$ \\ ${ }^{1}$ Balikesir University, Faculty of Science and Literature, Department of Chemistry, 10145 \\ Balikesir, Turkey \\ ${ }^{2}$ Balikesir University Faculty of Engineering, Department of Environmental Engineering \\ 10145 Balikesir, Turkey \\ ${ }^{3}$ Paşaalanı Mahallesi Karesi-Balıkesir, Turkey \\ *mdogan@balikesir.edu.tr
}

\title{
SYNTHESIS, CHARACTERIZATION AND THEIR ANTIMICROBIAL ACTIVITIES OF BORON OXIDE/POLY(ACRYLIC ACID) NANOCOMPOSITES: THERMAL AND ANTIMICROBIAL PROPERTIES
}

\begin{abstract}
Boron oxide $\left(\mathrm{B}_{2} \mathrm{O}_{3}\right) /$ Poly(acrylic acid) (PAA) nanocomposites were synthesized by solution intercalation method, and characterized by Fourier transform infrared spectroscopy (FTIR-ATR), transmission electron microscopy (TEM), X-ray diffraction and thermogravimetric analysis (DTA/TG). The effect of boron oxide amount on the thermal stability of nanocomposites was investigated. Moreover, the antimicrobial activities of them were also determined by the serial dilution method against $E$. coli and $S$. aureus. XRD analysis showed that boron oxide was homogenously dispersed in polymer matrix; FTIR-ATR that there was interaction between PAA and boron oxide; and TEM that boron oxide particles had spherical structure, and dispersed in nano size in polymer matrix; DTA/TG that the thermal stability of polymers increased with the adding of boron oxide into polymer matrix, and changed the decomposition mechanism of PAA. $\mathrm{B}_{2} \mathrm{O}_{3} / \mathrm{PAA}$ nanocomposites exhibited higher decomposition temperature. The decomposition mechanisms of PAA and its nanocomposites occurred through three decomposition steps; dehydration, decarboxylation and chain scission. $\mathrm{B}_{2} \mathrm{O}_{3} / \mathrm{PAA}$ nanocomposites showed greater antimicrobial activity with increasing $\mathrm{B}_{2} \mathrm{O}_{3}$ amount.
\end{abstract}

Keywords: Boron oxide, poly(acrylic acid), thermal stability, nanocomposite, antimicrobial activity

\section{INTRODUCTION}

The design and development of nanoparticles and nanostructural materials have opened a new area for constructing well-designed nanostructures that have been considered as a novel class of materials for catalytic, optical, electronic and biomedical applications [1]. In this area, nanocomposites are a relatively new family of composite materials in which, at least one of the dimensions of the filler, is in the nanometer range [2]. Nanocomposite materials based on polymeric matrices containing inorganic nano-materials have been intensively studied in recent years because the introduction of an inorganic phase dispersed at a nanoscale into the polymer matrix allows to obtain a final product with enhanced performances [3]. In general, polymer nanocomposites are made by dispersing of inorganic or organic nanoparticles into 
either a thermoplastic or thermoset polymer offering remarkable improvement in performance properties of the polymer [2].

Poly(acrylic acid) (PAA) $\left(\left(\mathrm{C}_{3} \mathrm{H}_{4} \mathrm{O}_{2}\right)_{n}\right)$, a water soluble thermoplastic polymer, has safely been used in numerous clinical applications such as drugs, body creams and pharmaceuticals, in many everyday products such as foods and cosmetics and in many fields of human activity such as production of paint, varnish, paper and emulsions [4]. The structure of PAA has been given in Figure 1. In recent years, different PAA composite materials have also been synthesized. Regenerated cellulose/poly(acrylic acid) composite films have been synthesized for wound dressing applications [5]. Electrically conductive CuS-PAA composites were prepared using chemically precipitated $\mathrm{CuS}$ powder from aqueous solution of poly(acrylic acid) [6]. $\mathrm{Fe}_{3} \mathrm{O}_{4} /$ chitosan/poly(acrylic acid) composite particles, which are reusable, biodegradable and high adsorption capacity, were prepared through polymerizing acrylic acid in chitosan and $\mathrm{Fe}_{3} \mathrm{O}_{4}$ nanoparticles' aqueous solution and were applied for adsorbing copper ion [7]. Nanoparticles may be three-dimensional nano metal oxides [8,9], two-dimensional layered silicates such as nanoclays [10], and one-dimensional carbon nanotubes [11]. Some oxides such as, $\mathrm{ZnO}, \mathrm{MgO}$ and $\mathrm{TiO}_{2}$, etc. are used extensively to construct functional coatings and bionanocomposites because of their stability under harsh processing conditions and safety in animal and human applications. Moreover, these materials offer antimicrobial, antifungal, antistatic and UV blocking properties [12].

Boron and boron-related compound nanostructures have received much interest recently because they are predicted to possess unique properties, such as high temperature stability, high wear resistant material for manufacturing cutting tools and abrasives [13]. $\mathrm{B}_{2} \mathrm{O}_{3}$ has a lot of application in industry as an essential fluxing agent for glasses and enamels, a basic component for boron and borosilicate glasses, an additive for optical fibers or as an acid catalyst in organic synthesis [14]. The general benefits of $\mathrm{B}_{2} \mathrm{O}_{3}$ in glass formulations are reduction of melting temperature, increased thermal resistance and mechanical strength, and enhanced aqueous and chemical durability. Borosilicate glass has increased thermal shock resistance because $\mathrm{B}_{2} \mathrm{O}_{3}$ have lowers expansion coefficient [15].

In this paper, a series of $\mathrm{B}_{2} \mathrm{O}_{3} / \mathrm{PAA}$ nanocomposite materials were prepared by effectively dispersing of nano $\mathrm{B}_{2} \mathrm{O}_{3}$ particles into PAA matrix via solution intercalation technique. The effect of nano $\mathrm{B}_{2} \mathrm{O}_{3}$ amount on the properties of nanocomposites was investigated. The synthesized nanocomposite materials were characterized by Fouriertransformation infrared (FTIR) spectroscopy, X-ray diffraction (XRD), transmission electron microscopy (TEM) and DTA/TG. Moreover, antimicrobial activity of nanocomposites was also determined.

\section{MATERIALS AND METHODS}

\section{Materials}

Poly(acrylic acid), which has a molecular weight of 45,000 g/mol, was supplied from SigmaAldrich; boron oxide from Riedel-de Haen, and xylene from Merck Chemical Co., Fig.1.

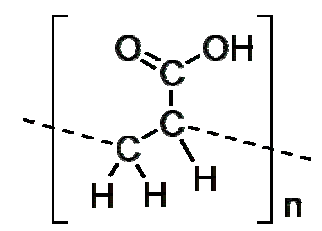

Fig. 1. Structure of PAA 


\section{$\mathrm{B}_{2} \mathrm{O}_{3} / \mathrm{PAA}$ nanocomposites}

$\mathrm{B}_{2} \mathrm{O}_{3} /$ PAA nanocomposites were synthesized by the solution intercalation method. Firstly, PAA was solved by stirring in xylene at $25^{\circ} \mathrm{C}$ for $20 \mathrm{~h}$. Then, $\mathrm{B}_{2} \mathrm{O}_{3}$ was added into the polymer solutions at different $\mathrm{B}_{2} \mathrm{O}_{3} / \mathrm{PAA}$ weight ratios (1, 2.5 and $\left.5 \mathrm{wt} . \%\right)$. Finally, PAA and $\mathrm{B}_{2} \mathrm{O}_{3}$ were mixed together for $24 \mathrm{~h}$. The mixtures were poured into teflon Petri dishes and dried at $50^{\circ} \mathrm{C}$ in a vacuum oven [16].

\section{Characterization}

X-ray powder diffraction (XRD) measurements were performed at $25^{\circ} \mathrm{C}$ on an Analytical Philips X'Pert-Pro X-ray diffractometer equipped with a back monochromator operating at 40 $\mathrm{kV}$ and a $\mathrm{Cu}$ cathode as the X-ray source $\left(\mathrm{k}_{\alpha}=1.54 \AA\right)$. FTIR spectra of samples were taken in the range from 4000 to $650 \mathrm{~cm}^{-1}$ in the transmission mode using a Perkin Elmer Spectrum 100 FTIR-ATR. Thermogravimetric analyses were performed using Perkin Elmer Diamond simultaneous DTA/TG instrument with a heating rate of $10^{\circ} \mathrm{C} / \mathrm{min}$ from $25^{\circ} \mathrm{C}$ to $600^{\circ} \mathrm{C}$ under $\mathrm{N}_{2}$ atmosphere. TEM photographs of $\mathrm{B}_{2} \mathrm{O}_{3}$ and $\mathrm{B}_{2} \mathrm{O}_{3} /$ PAA nanocomposites were taken with FEI Tecnai G2 F30 transmission electron microscope using an acceleration voltage of 200 $\mathrm{kV}$.

\section{Antimicrobial activity}

The antibacterial assays were carried out against gram-negative Escherichia coli and gram-positive Stafilococcus aureus bacteria. The gram-negative bacteria, E. coli ATCC-8739, and gram-positive bacteria, S. aureus ATCC-6538 stock cultures were grown in tryptic soy (TS) broth. Bacteria colonies were quantified after aerobically incubation at $37^{\circ} \mathrm{C}$ for $24 \mathrm{~h}$. Antimicrobial effects of PAA and its nanocomposites were determined by blocking reproductive of colonies both of the bacteria solid media [1].

\section{RESULTS AND DISCUSSION}

\section{XRD analysis}

Figure 2 has shown the powder X-ray diffraction patterns of PAA, $\mathrm{B}_{2} \mathrm{O}_{3}$ and their nanocomposites synthesized in the presence of different amounts of $\mathrm{B}_{2} \mathrm{O}_{3}$. No peak appears in the XRD pattern of the poly(acrylic acid). This shows that PAA is a polymer in the amorphous structure in nature. Boron oxide powder has specific peaks at $2 \theta=15^{\circ}, 28^{\circ}$ and $45^{\circ}$ [17].

These peaks did not appear in the case of nanocomposite. This may be due to the fact that the nanoparticles in the polymer matrix are not well dispersed or that the $\mathrm{B}_{2} \mathrm{O}_{3}$ particles into the polymer matrix have weak intensities. In this case the XRD peaks of the boron oxide can remain below the peaks of the polymer and these peaks do not appear in the XRD pattern. All nanocomposites exhibited a similar and homogeneous distribution in XRD patterns. 


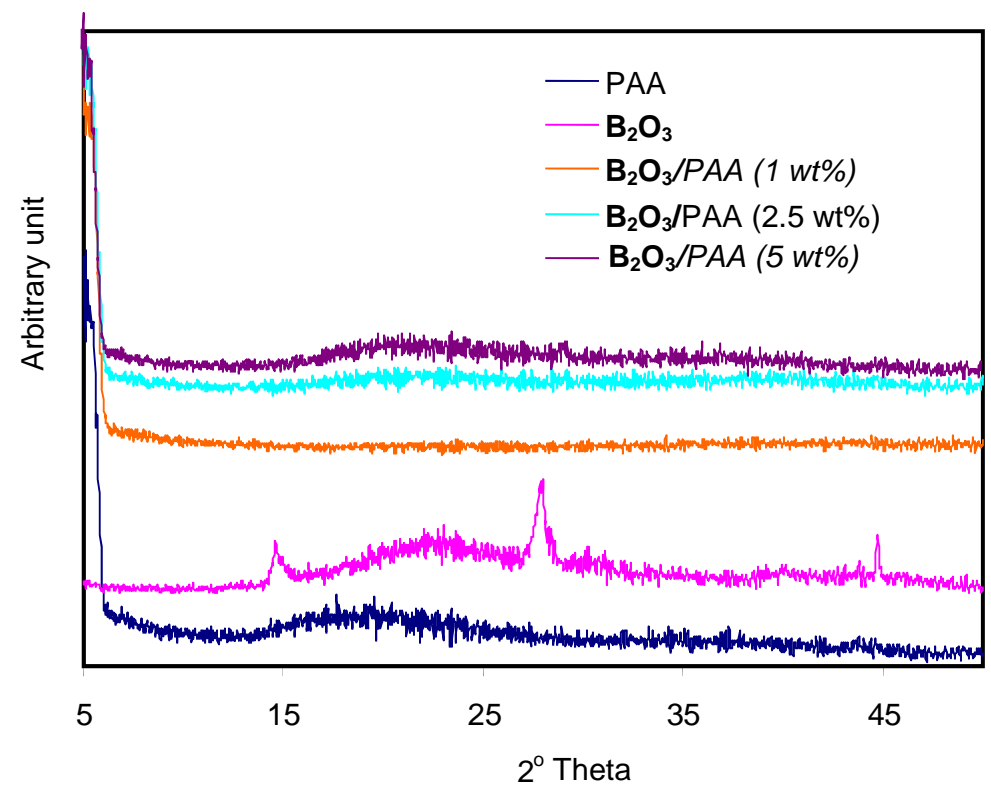

Fig. 2. XRD pattern of $P A A, B 2 O 3$ and their nanocomposites

FTIR analysis

Figure 3 has shown FTIR-ATR spectra of boron oxide, PAA and their nanocomposites at $4000-650 \mathrm{~cm}^{-1}$.

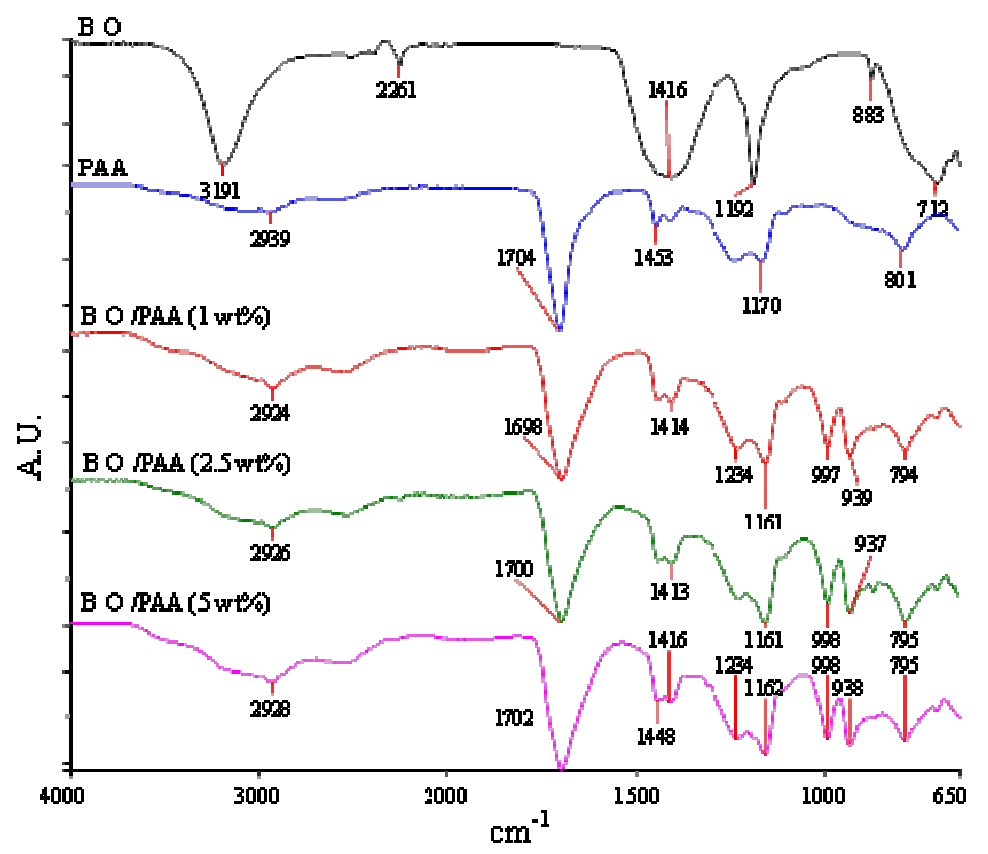

Fig. 3. FTIR-ATR spectra of PAA, B2O3 and their composites

Boron oxide has strong absorption peaks at about 3191 and $1192 \mathrm{~cm}^{-1}$ due to B-O-H stretching peaks, weak absorption peaks at $2261-2510 \mathrm{~cm}^{-1}$ due to B-H vibration and broad absorption peak at $1416 \mathrm{~cm}^{-1}$ due to B-O vibration [18]. FTIR-ATR spectra of PAA have shown the characteristic stretching band of carboxylic group $(\mathrm{C}=\mathrm{O})$ at $\sim 1704 \mathrm{~cm}^{-1}, \mathrm{CH}$ stretch 
band between $3000-2800 \mathrm{~cm}^{-1}, \mathrm{CH}_{2}$ bending band in $1453 \mathrm{~cm}^{-1}$, coupling between $\mathrm{OH}$ and $\mathrm{CO}$ of in-plane $\mathrm{OH}$ bending and $\mathrm{CO}$ stretching of neighboring, and $\mathrm{C}-\mathrm{O}$ band in about 1170 and $1046 \mathrm{~cm}^{-1}[3,19]$. The peak at $2939 \mathrm{~cm}^{-1}$ is due to $\mathrm{C}-\mathrm{H}$ stretching of polymer backbone [20]. There are two new peaks for $\mathrm{B}_{2} \mathrm{O}_{3} / \mathrm{PAA}$ nanocomposites at around 997 and $939 \mathrm{~cm}^{-1}$ and this new peaks may be related with the interaction between $\mathrm{OH}$ group on the $\mathrm{B}_{2} \mathrm{O}_{3}$ surface and $\mathrm{COOH}$ unit of PAA as shown in following reaction(1) [17]:<smiles></smiles>

In addition, a peak at $883 \mathrm{~cm}^{-1}$ in the FTIR spectrum of boron oxide appeared. The same peak was also observed in the FTIR spectra of the boron oxide/PAA (especially $2.5 \mathrm{wt} \%$ and $5 \mathrm{wt} \%$ ) nanocomposites. This peak was also evidence that boron oxide/PAA nanocomposites were synthesized.

\section{TG analysis}

TG data of PAA and $\mathrm{B}_{2} \mathrm{O}_{3} / \mathrm{PAA}$ nanocomposites were calculated from their $\mathrm{TG}$ and $\mathrm{d}[\mathrm{TG}]$ curves under $\mathrm{N}_{2}$ atmosphere (Figures not shown) and those shown in Table 1.

Table 1. $T G$ and $d[T G]$ values of $P A A, B_{2} \mathrm{O}_{3}$ and their nanocomposites

\begin{tabular}{lccc}
\hline \multirow{2}{*}{ Sample } & Decomposition steps & $\begin{array}{c}\text { Inflection point } \\
\left({ }^{0} \mathrm{C}\right)\end{array}$ & $\begin{array}{c}\text { Weight loss } \\
(\%)\end{array}$ \\
\hline \multirow{2}{*}{$\mathrm{PAA}$} & 1 & 65 & 2.2 \\
& 2 & 297 & 29.1 \\
& 3 & 410 & 66.8 \\
\hline $\mathrm{B}_{2} \mathrm{O}_{3} /$ PAA $(1 \mathrm{wt} \%)$ & 1 & 210 & 17.3 \\
& 2 & 317 & 22.2 \\
& 3 & 436 & 42.6 \\
$\mathrm{~B}_{2} \mathrm{O}_{3} /$ PAA $(2.5 \mathrm{wt} \%)$ & 1 & 205 & 18.8 \\
& 2 & 320 & 25.5 \\
& 3 & 438 & 42.2 \\
$\mathrm{~B}_{2} \mathrm{O}_{3} /$ PAA $(5 \mathrm{wt} \%)$ & 1 & 210 & 22.4 \\
& 2 & 321 & 28.2 \\
& 3 & 433 & 51.0 \\
\hline
\end{tabular}


Calculated data in Table 1 has shown that the thermal degradation of PAA and $\mathrm{B}_{2} \mathrm{O}_{3} / \mathrm{PAA}$ nanocomposites occurs through three decomposition steps; dehydration, decarboxylation and chain scission [21]. For pure PAA, the first step has occurred between 30 and $150^{\circ} \mathrm{C}$ with an inflection point at $65^{\circ} \mathrm{C}$ because of dehydration which may occur by intra or intermolecular reaction of carboxyl groups. The first mass loss in the temperature range of $30-150{ }^{0} \mathrm{C}$ is due to the evaporation of physically weakly and chemically strongly bound $\mathrm{H}_{2} \mathrm{O}$. The initial step in the thermal degradation involves the formation of anhydride structures. The majority of these anhydrides involve the formation of six-membered glutaric anhydride rings by the reaction of adjacent acid groups [22]. PAA has $2.2 \mathrm{wt} \%$ weight loss at this step. Separation of $\mathrm{CO}_{2}$ as gas shows the decarboxylation of anhydride structures and keten, ketone and unsaturated compounds forming intermediate compounds. The second step which contains decarboxylation occurs between 150 and $320{ }^{\circ} \mathrm{C}$ with an inflection point at $297^{\circ} \mathrm{C}$ and weight loss of $29.1 \mathrm{wt} \%$. This case can be seen as following equation:

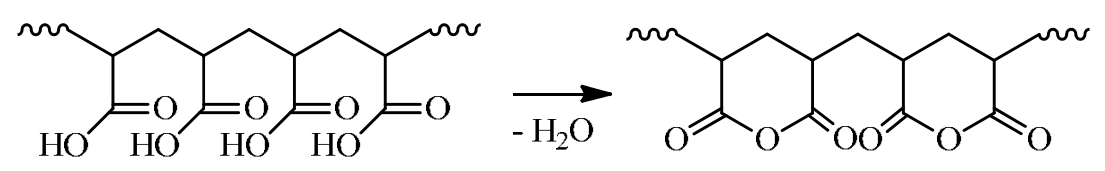

The chain scission occurs as third step between 320 and $550^{\circ} \mathrm{C}$ with an inflection point at $410{ }^{\circ} \mathrm{C}$ and weight loss of $66.8 \mathrm{wt} \%$, where the formation of important amounts of cold ring fraction consisting of dimers, trimers, etc. are possible owing to release of fragments with short sequences of acrylic acid [21]. Acrylic acid monomers far away from the structure represent depolymerization reaction $[21,23]$.

The $\mathrm{B}_{2} \mathrm{O}_{3} / \mathrm{PAA}$ nanocomposites have also three decomposition steps. All data were summarized in Table 1. The first dehydration step for all nanocomposites occurred at about $210{ }^{\circ} \mathrm{C}$ with an increasing weight loss because of the $\mathrm{B}_{2} \mathrm{O}_{3}$ surface water release with dehydration of PAA. In the case of nanocomposites, the second inflection temperature of the polymer increases while the weight loss decreases. This may be due to the possible interaction between $\mathrm{OH}$ group on $\mathrm{B}_{2} \mathrm{O}_{3}$ surface and $\mathrm{COOH}$ unit of PAA and this interaction may also reduce decarboxylation of the polymer. Also, second step inflection point has a $10{ }^{0} \mathrm{C}$ increment. As can be seen from the Table 1, the second and third step beginning temperatures for the nanocomposites are higher than pure PAA. Also, the chain scission amount is lower than pure PAA according the third step weight loss. All data shows that $\mathrm{B}_{2} \mathrm{O}_{3} / \mathrm{PAA}$ nanocomposites are more stable than pure PAA with increasing temperature. A similar thermal behavior was observed for Al-pillared-montmorillonite (AlPMt)/poly(methyl methacrylate)(PMMA) nanocomposites synthesized via melt blending method and solution blending method [24], and for polystyrene/expanded graphite nanocomposites prepared using solution blending technique [25].

\section{TEM analysis}

TEM allows a qualitative understanding of the internal structure, spatial distribution of the various phases, and views of the defect structure through direct visualization [26]. The internal structures of the nanocomposites and $\mathrm{B}_{2} \mathrm{O}_{3}$ particles in the nanometer scale have been shown at Fig. 4. TEM photos have indicated that $\mathrm{B}_{2} \mathrm{O}_{3}$ particles are well dispersed in the polymer matrix and the $\mathrm{B}_{2} \mathrm{O}_{3}$ particle size is under $100 \mathrm{~nm}$. 

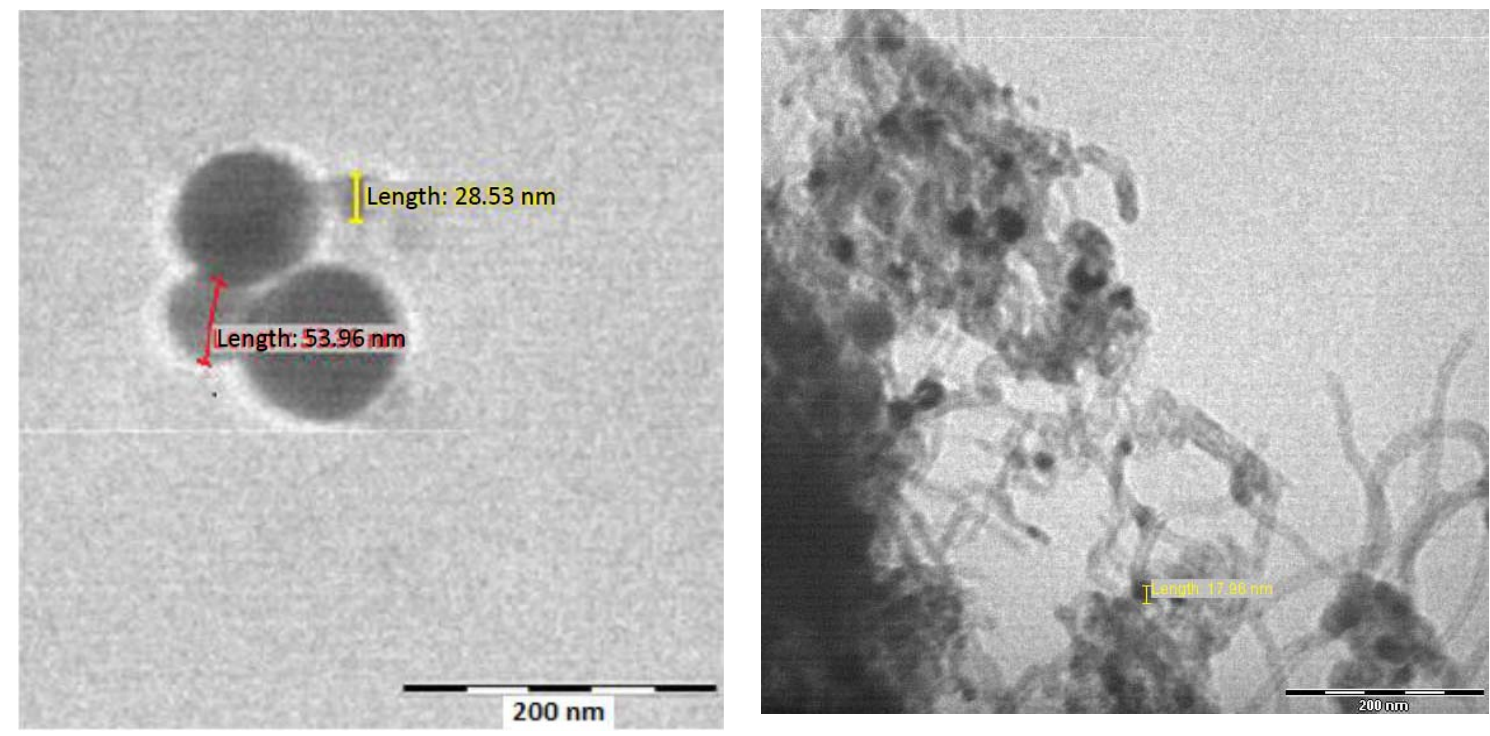

Fig. 4. TEM images of $\mathrm{B} 2 \mathrm{O} 3$ and $\mathrm{B} 2 \mathrm{O} / \mathrm{PAA}$ nanocomposites

\section{Antibacterial results}

Figure 5 has shown the antimicrobial activity of PAA and its nanocomposites against $E$. coli and $S$. aureus. The inhibition zones surrounding the film have shown that $\mathrm{B}_{2} \mathrm{O}_{3} / \mathrm{PAA}$ nanocomposites have antibacterial activity. On the other hand, the results as depicted in Figure 5 clearly indicated that when PAA was applied to cultivation both of $E$. coli and $S$. aureus, there was not noticeable inhibition. Compared to E. coli, experimental results show that nanocomposites have more antibacterial activity for $S$. aureus with increasing boron oxide content. This is probably because of the difference in cell walls between the gramnegative bacteria and gram-positive bacteria. As a result, the synthesized nanocomposites had different antimicrobial effect on $E$. coli and $S$. aureus.

a

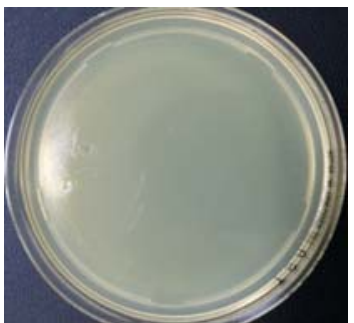

PAA

b

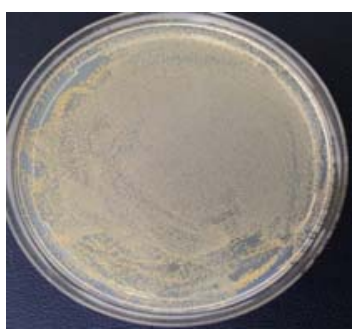

PAA

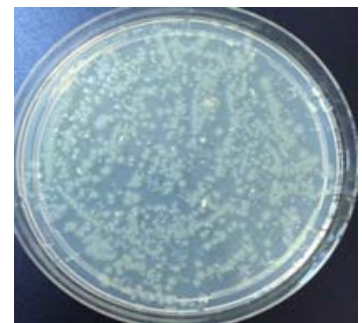

$\mathrm{B}_{2} \mathrm{O}_{3} / \mathrm{PAA}(1 \mathrm{wt} \%)$

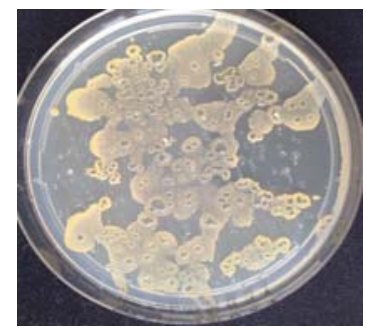

$\mathrm{B}_{2} \mathrm{O}_{3} /$ PAA (1 wt $\left.\%\right)$

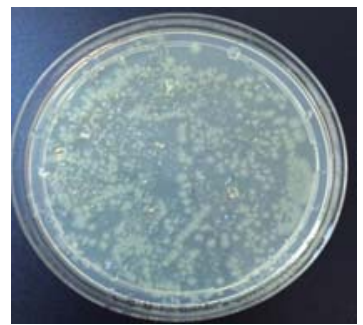

$\mathrm{B}_{2} \mathrm{O}_{3} /$ PAA (2.5 wt $\left.\%\right)$

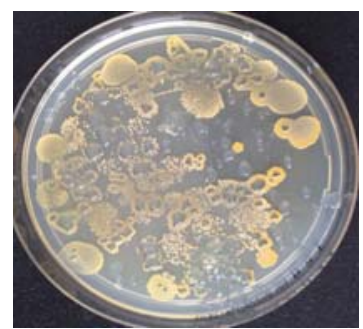

$\mathrm{B}_{2} \mathrm{O}_{3} /$ PAA (2.5 wt $\left.\%\right)$

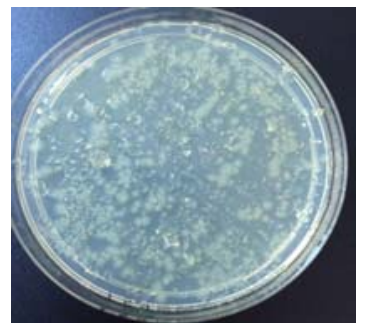

$\mathrm{B}_{2} \mathrm{O}_{3} / \mathrm{PAA}(5 \mathrm{wt} \%$ )

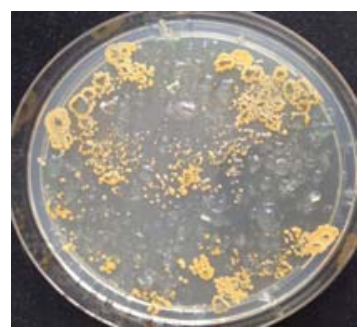

$\mathrm{B}_{2} \mathrm{O}_{3} / \mathrm{PAA}(5 \mathrm{wt} \%)$

Fig. 5. Antimicrobial activity of PAA and its nanocomposites against a. E. coli and b. S. aureus 


\section{CONCLUSIONS}

$\mathrm{B}_{2} \mathrm{O}_{3} / \mathrm{PAA}$ nanocomposites were synthesized in xylene solvent using solution intercalation method and characterized with different methods. The nanocomposites have the characteristic peaks of PAA for FTIR and XRD measurements. New peaks which indicates possible interaction of PAA and $\mathrm{B}_{2} \mathrm{O}_{3}$ has been obtained for all nanocomposite spectrums. These new peaks were related to new $\mathrm{H}$-bonds which could occur between $\mathrm{OH}$ group on $\mathrm{B}_{2} \mathrm{O}_{3}$ surface and carboxyl group of PAA. Nanocomposites showed higher thermal stability than pure PAA. The temperatures of all three steps of decomposition had remarkably incremented compared to pure PAA. Nanocomposites had at a high degree of antimicrobial activity against both bacteria.

\section{ACKNOWLEDGEMENTS}

This investigation was supported by National Boron Research Institute (BOREN 2009.Ç0231).

\section{REFERENCES}

1. Thomas V., Yallapu M.M., Sreedhar B., Bajpai S.K., A versatile strategy to fabricate hydrogelsilver nanocomposites and investigation of their antimicrobial activity. J. Colloid. Interface Sci., 315 (2007), 389-395.

2. Turhan Y., Alp Z.G., Alkan M., Doğan M., Preparation and characterization of poly(vinylalcohol)/modified bentonite nanocomposites. Microporous and Mesoporous Mater., 174 (2013), 144-153.

3. Hojjati B., Sui R., Charpentier P.A., Synthesis of $\mathrm{TiO}_{2} / \mathrm{PAA}$ nanocomposite by RAFT polymerization. Polymer, 48 (2007), 5850-5858.

4. Wisniewska M., Nosal-Wiercinska A., Dabrowska I., Szewczuk-Karpisz K., Effect of the solid pore size on the structure of polymer film at the metal oxide/polyacrylic acid solution interface Temperature impact. Microporous and Mesoporous Mater., 175 (2013), 92-98.

5. Bajpai M., Bajpai S.K., Gautam D. Investigation of regenerated cellulose/poly(acrylic acid) composite films for potential wound healing applications: A preliminary study. J. Appl. Chem., (2014), Article ID 325627.

6. Hu H., Campos J., Nair P.K., Electrically conductive CuS-poly(acrylic acid) composite coatings. J. Mater. Res., 11(3) (1996), 739-745.

7. Zhang S., Zhou Y.F., Nie W.Y., Song L.Y., Preparation of $\mathrm{Fe}_{3} \mathrm{O}_{4} /$ chitosan/poly(acrylic acid) composite particles and its application in adsorbing copper ion (II). Cellulose, 19 (2012), 20812091.

8. Lecerf N., Mathur S., Shen H., Veith M., Hufner S., Chemical vapour and sol-gel syntheses of nano-composites and -ceramics using metal-organic precursors. Scr. Mater., 44(8-9) (2001), 2157-2160.

9. Kunitake N., Fujikawa S., Nanocopying as a means of 3D nanofabrication: scope and prospects. Aust J Chem., 56(10) (2003), 1001-1003.

10. Lee T.W., Park O.O., Yoon J., Kim J.J., Polymer-layered silica nanocomposite light emitting devices. Adv. Mater. 13 (2001), 211-213. 
11. McEuen P.L., Bockrath M., Cobden D.H., Lu J.G., Nanotechnology: principles and fundamentals. Microelectron Eng., 47(4) (1999), 417-420.

12. Rouhi J., Mahmud S., Naderi N., Raymond C.H., Mahmood M.R., Physical properties of fish gelatin-based bio-nanocomposite films incorporated with $\mathrm{ZnO}$ nanorods. Nanoscale Res. Lett., 8 (2013), 364.

13. Alizadeh M., Sharifianjazi F., Haghshenasjazi E., Aghakhani M., Rajabi L., Production of nanosized boron oxide powder by high-energy ball milling. Synthesis and Reactivity in Inorganic, Metal-Organic, and Nano-Metal Chemistry, 45 (2015), 11-14.

14. Pittoni P.G., Chang Y.Y., Lin S.Y., Interpretation of the peculiar temperature dependence of surface tension for boron trioxide. J. Taiwan. Inst. Chem. Eng., 43 (2012), 852-859.

15. Woods W.G., An Introduction to boron: history, sources, uses, and chemistry. Environ. Health Perspect., 102 (1994), 5-11.

16. Turhan Y., Dogan M., Alkan M., Poly(vinyl chloride)/kaolinite nanocomposites: characterization and thermal and optical properties. Ind. Eng. Chem. Res., 49 (2010), 1503-1513.

17. Töre İ., Ay N., The Characterization and production of amorphous boron oxide. 2. International Boron Congress. September 23-25, Eskişehir/TURKEY.

18. Moon O.M., Kang B.C., Lee S.B., Boo J.H., Temperature effect on structural properties of boron oxide thin films deposited by MOCVD method. Thin Solid Films, 464-465 (2004), 164-169.

19. Moharram M.A., Rabie S.M., El-Gendy H.M., IR spectra of -irradiated PAA-PAAm complex. J Appl. Polym. Sci., 85(8) (2002), 1619-1623.

20. Mohammed A.M., Radia N.D., Controlled release from crosslinked polyacrylic acid as drug delivery theophylline. Irq. Nat. J. Chem., 45 (2012), 67- 85.

21. De la Fuente J.L., Wilhelm M., Spiess H.W., Madruga E.L., Fernandez-Garcia M., Cerrada M.L., Thermal, morphological and rheological characterization of poly(acrylic acid-g-styrene) amphiphilic graft copolymers. Polymer, 46 (2005), 4544-4553.

22. McGaugh M.C., Kottle S., The thermal degradation of poly(acrylic acid). J. Polym. Sci. B., 5(9) (1967), 817-820.

23. Dubinsky S., Grader G.S., Shter G.E., Silverstein M.S., Thermal degradation of poly(acrylic acid) containing copper nitrate. Polym. Degrad. Stab., 86 (2004), 171-178.

24. Kızılduman B.K., Alkan M., Doğan M., Turhan Y., Al-pillared-montmorillonite (AlPMt)/Poly(methylmethacrylate)(PMMA) nanocomposites: the effects of solvent types and synthesis methods. Adv. Mat. Sci., 17(3) (2017), 5-23.

25. Kausar A., Ullah W., Muhammad B., Siddiq M., Novel mechanically stable, heat resistant and nonflammable functionalized polystyrene/expanded graphite nanocomposites. Adv. Mat. Sci., 14(4) (2014) 61-74.

26. Ray S.S., Okamoto M. Polymer/layered silicate nanocomposites: a review from preparation to processing. Prog. Polym. Sci., 28 (2003), 1539-1641. 